\title{
Association between tumor-infiltrating lymphocytes and sentinel lymph node positivity in thin melanoma*
}

\author{
Fernando De Marco dos Santos ${ }^{1}$, Felipe Correa da Silva ${ }^{2}$, Julia Pedron², Roque Domingos Furian ${ }^{3}$, \\ Cristina Fortes ${ }^{4}$, Renan Rangel Bonamigo ${ }^{5,6}$
}

DOI: http:/ / dx.doi.org/10.1590/abd1806-4841.20197414

\begin{abstract}
BACKGROUND: Sentinel lymph node biopsy in thin invasive primary cutaneous melanoma (up to $1 \mathrm{~mm}$ thick) is a controversial subject. The presence of tumor-infiltrating lymphocytes could be a factor to be considered in the decision to perform this procedure.

Овлестіvе: To evaluate the association between the presence of tumor-infiltrating lymphocytes and lymph node metastases caused by thin primary cutaneous melanoma.

MEtHods: Cross-sectional study with 137 records of thin invasive primary cutaneous melanoma submitted to sentinel lymph node biopsy from 2003 to 2015. The clinical variables considered were age, sex and topography of the lesion. The histopathological variables assessed were: tumor-infiltrating lymphocytes, melanoma subtype, Breslow thickness, Clark levels, number of mitoses per $\mathrm{mm}^{2}$, ulceration, regression and satellitosis. Univariate analyzes and logistic regression tests were performed as well the odds ratio and statistical relevance was considered when $\mathrm{p}<0.05$.

RESUlTs: Among the 137 cases of thin primary cutaneous melanoma submitted to sentinel lymph node biopsy, 10 (7.3\%) had metastatic involvement. Ulceration on histopathology was positively associated with the presence of metastatic lymph node, with odds ratio $=12.8(2.77-59.495 \% \mathrm{CI}, \mathrm{p}=0.001)$. The presence of moderate/marked tumor-infiltrating lymphocytes was shown to be a protective factor for the presence of metastatic lymph node, with $\mathrm{OR}=0.20(0.05-0.7295 \% \mathrm{CI}$, p=0.014). The other variables - clinical and histopathological - were not associated with the outcome.

STUDY LIMITATIONS: The relatively small number of positive sentinel lymph node biopsy may explain such an expressive association of ulceration with metastatization.

CONCLUSIONS: In patients with thin invasive primary cutaneous melanoma, few or absent tumor-infiltrating lymphocytes, as well as ulceration, represent independent risk factors for lymph node metastasis.
\end{abstract}

Keywords: Lymphocytes, tumor-infiltrating; Medical oncology; Melanoma; Sentinel lymph node biopsy

\section{INTRODUCTION}

Early diagnosis of melanoma is a vital necessity in view of the reduced survival with the progression of the disease. In invasive early lesions, i.e., up to $1 \mathrm{~mm}$ thickness and not in situ, lymph node involvement is one of the main prognostic factors. ${ }^{1,2}$ Thus, tumors classified as $\mathrm{T} 1$ ( $\leq 1 \mathrm{~mm}$ thick) by the American Joint Committee on Cancer (AJCC), despite representing the majority of melanomas
(63\%), can belong to clinical stage III (due to lymph node involvement) and patients have their 5-year survival significantly reduced (98.9\% for $\mathrm{T} 1 \mathrm{a}$ and $93.7 \%$ for $\mathrm{T} 1 \mathrm{~b}$ ) to $53.7 \% .{ }^{3,4}$ This explains the fact that thin melanomas being responsible for up to $25 \%$ of death caused by this disease. ${ }^{3}$

Received 13 July 2017.

Accepted 13 December 2017.

* Work conducted at Universidade Federal de Ciências da Saúde de Porto Alegre, Porto Alegre (RS), Brazil.

Financial support: None.

Conflict of interest: None.

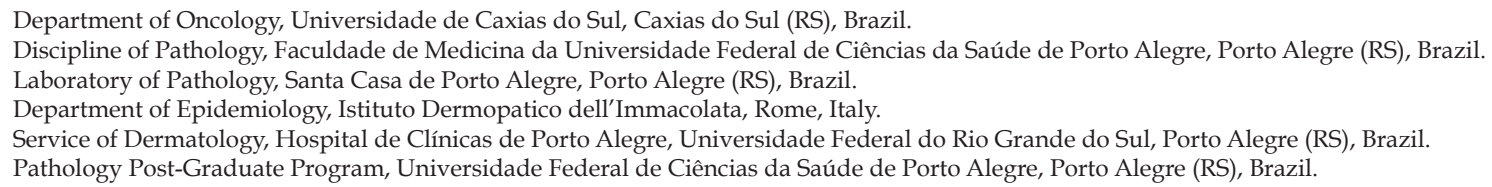


The recommendation for sentinel lymph node biopsy (SLNB) in a thin cutaneous melanoma $(\leq 1 \mathrm{~mm})$ is controversial since some authors consider the chance of lymph node involvement to be low in this group, particularly when the thickness is of less than $0.75 \mathrm{~mm} \cdot{ }^{5-10}$ On the other hand, some authors present data that add to the existing doubts on the subject. Fearfield et al. ${ }^{11}$ found 2 to $18 \%$ of recurrence in up to 11 years when melanoma thickness was less than $0.76 \mathrm{~mm}$ and Andtbacka \& Gershenwald ${ }^{12}$ argued that $5.1 \%$ of positive lymph nodes (LN) in thin primary cutaneous melanomas (TPCM) would be enough to support the universalization of screening.

Tumor-infiltrating lymphocytes (TIL) play a central role in targeted-therapy revolution. ${ }^{13-15}$ Its understanding triggered advances in immunotherapy and their presence represents a favorable outcome with improved survival. ${ }^{16}$

The classification of the activity of TIL remained the same for approximately 30 years, since it was first categorized into brisk and non-brisk. ${ }^{17}$ A new classification was proposed with the addition of another level in lymphocytic activity, with standardization into few, moderate and marked. This new sub-classification was used in the study by Fortes. ${ }^{18,19}$

The main objective of this study was to investigate the relationship between metastatic involvement of sentinel lymph node and the presence and intensity of tumor-infiltrating lymphocytes. The secondary objectives were to compare the other clinical characteristics and pathological microstaging with the same outcome.

\section{METHODS}

Cross-sectional study conducted with data registered between 2003 and 2015 in the Laboratory of Pathology, Santa Casa de Porto Alegre, an oncology reference center in the south of Brazil. Cases with invasive lesions $\leq 1 \mathrm{~mm}$, with no clinical lymph node involvement, submitted to SLNB were eligible. Clinical and histological variables were assessed: age, sex, topography of the lesion, histological subtype, presence of TIL (graded into few, moderate and marked), Breslow thickness, Clark levels, mitoses, ulceration, regression and satellitosis. The study was approved by the committee of ethics in research of the institution under the number 653.823.

After the diagnosis of melanoma with excisional biopsy, the patients were submitted to staging with clinical examination and imaging studies. In the immediate pre-operative period, the patients were reassessed and only those cases with no lymph node involvement were included in the study, ruling out the possibility of over-indicating SLNB in view of an already existing indication for lymphadenectomy. All SLNB negative on examination with hematoxylin \& eosin were submitted to immunohistochemistry. All patients diagnosed with secondary implants in the sentinel lymph nodes were submitted to lymphadenectomy.

For the statistical analysis, the level of significance adopted was $5 \%(p<0.05)$ and the analyses were made using the program SPSS version 21.0. The main outcome was metastatic involvement of the sentinel lymph node. The Odds Ratio (OR), together with the 95\% confidence interval, was calculated to estimate the effect of each factor on the main outcome. The ROC (Receiver Operating Characteristic) curve was evaluated to estimate the best cut-off point for Breslow thickness according to sentinel lymph node positivity and the area on the curve was calculated to estimate the accuracy of this score for predicting the outcome. Student's T test was used for the comparison of the means between patients with and without sentinel lymph node involvement. In case of asymmetry, the Mann-Whitney test was used. Fisher's exact test or Pearson's chi-square test (variables with more than two categories) were used in the comparison of proportions. Poisson regression was used for the multivariate analysis.

\section{RESULTS}

The mean age of the patients in the study was 53 years, with a non-significant predominance of females. The trunk was the site most affected by melanoma and the most frequent type of melanoma was the superficial spreading type (Table 1).

One hundred and thirty-seven cases of TPCM that had protocol indication for the procedure were submitted to SNLB (presence of ulceration, mitosis, thickness more than $0.75 \mathrm{~mm}$, regression), among which 10 (7.3\%) had metastatic lymph node involvement. After multivariate regression analysis, only two factors had statistical significance. The group that had moderate and marked TIL showed a reduction in the risk of sentinel lymph node involvement, with OR=0.2 (95\% CI: 0.02-0.72 and p=0.014), and those with ulceration had a 12.8-fold higher risk of lymph node metastatization: $\mathrm{OR}=12.8$ (95\% CI: 2.77-59.4 and $\mathrm{p}=0.001)$; these findings are shown in tables 1 and 2 .

In 4 cases, Breslow was less than $0.76 \mathrm{~mm}$. One of the cases of positive sentinel lymph node classified as low risk (Breslow 0.38, one mitosis per field, moderate TIL, presence of regression, negative clinical examination for lymph node enlargement, absent ulceration and satellitosis) had six metastatic lymph nodes out of six resected and resection of 25 more lymph nodes with no malignancy, constituting an exception case.

The ROC curve demonstrated a non-statistically significant $(p=0.282)$ tendency that thickness $\geq 0.79 \mathrm{~mm}$ would increase the chance of sentinel lymph node positivity.

The lowest Breslow thickness associated to positive sentinel lymph node was $0.31 \mathrm{~mm}$. In 4 cases $(40 \%)$, the identification of metastasis in sentinel lymph node was only possible with immunohistochemistry. Among the patients who were submitted to lymph node resection, there was metastatization to other lymph nodes in $50 \%$ of the lymph nodes detected with immunohistochemistry. For the sentinel lymph nodes positive on hematoxylin \& eosin, lymphadenectomy found other implants in $66 \%$ of cases. The mean number of resected lymph nodes was 27.5.

\section{DISCUSSION}

In the present study, the presence of moderate/marked TIL was a protection factor for the presence of metastatic lymph node. Patients with moderate/marked TIL in the primary melanoma lesion had a five-fold lower risk for the presence of one positive lymph node when compared to individuals with absent or few TIL in the lesion.

An increasing number of studies show that the individual immune response related to TIL can yield consistent results regarding improved survival, defining TIL as a prognostic factor. ${ }^{18-22}$ 
TABLE 1: Overall characteristics of the sample: patients with thin primary cutaneous melanomas and metastatic sentinel lymph node involvement (2003-2015, Laboratory of Pathology, Santa Casa de Porto Alegre, Brazil); n= 137

\begin{tabular}{|c|c|c|c|}
\hline \multirow[b]{2}{*}{ Variables } & \multicolumn{2}{|c|}{ SLN involvement } & \multirow[b]{2}{*}{$P^{*}$} \\
\hline & Yes $(n=10 ; 7.3 \%)$ & No $(n=127 ; 92.7 \%)$ & \\
\hline Age (years) & $52.1 \pm 12.5$ & $53.9 \pm 13.4$ & 0.682 \\
\hline Sex $-n(\%)$ & - & - & 0.104 \\
\hline Male & $7(70.0)$ & $53(41.7)$ & - \\
\hline Female & $3(30.0)$ & $74(58.3)$ & - \\
\hline Location - n (\%) & & & 0.533 \\
\hline Lower limbs & $0(0.0)$ & $22(17.3)$ & - \\
\hline Trunk & $6(60.0)$ & $61(48.0)$ & - \\
\hline Head and neck & $2(20.0)$ & $10(7.9)$ & - \\
\hline Upper limbs & $2(20.0)$ & $27(21.3)$ & - \\
\hline Vulva & $0(0.0)$ & $1(0.8)$ & - \\
\hline Acral & $0(0.0)$ & $6(4.7)$ & - \\
\hline Type - n (\%) & & & 0.567 \\
\hline Superficial spreading & $9(90.0)$ & $113(89.0)$ & - \\
\hline Lentigo & $0(0.0)$ & $8(6.3)$ & - \\
\hline Nodular & $1(10.0)$ & $6(4.7)$ & - \\
\hline Clark - n (\%) & & & 0.005 \\
\hline I & $0(0.0)$ & $1(0.8)$ & - \\
\hline II & $1(10.0)$ & $44(34.6)$ & - \\
\hline III & $5(50.0)$ & $52(40.9)$ & - \\
\hline IV & $3(30.0)$ & $30(23.6)$ & - \\
\hline $\mathrm{V}$ & $1(10.0)$ & $0(0.0)$ & - \\
\hline Breslow - mean \pm SD & $0.68 \pm 0.26$ & $0.65 \pm 0.24$ & 0.635 \\
\hline$<0,76$ & $5(50.0)$ & $76(59.8)$ & 0.740 \\
\hline$\geq 0,76$ & $5(50.0)$ & $51(40.2)$ & - \\
\hline Intensity of TIL - n (\%) & & & 0.080 \\
\hline Negative & $1(10.0)$ & $3(2.4)$ & - \\
\hline Few & $6(60.0)$ & $39(30.7)$ & - \\
\hline Moderate & $3(30.0)$ & $63(49.6)$ & - \\
\hline Marked & $0(0.0)$ & $22(17.3)$ & - \\
\hline Location TIL - n (\%) & & & 0.512 \\
\hline Peritumoral & $6 / 9(66.7)$ & $67 / 124(54.0)$ & - \\
\hline Peritumoral and intratumoral & $3 / 9(33.3)$ & $57 / 124(46.0)$ & - \\
\hline Regression - n (\%) & & & 0.096 \\
\hline Positive & $3(30.0)$ & $76(59.8)$ & - \\
\hline Negative & $7(70.0)$ & $51(40.2)$ & - \\
\hline Ulceration - n (\%) & & & 0.141 \\
\hline Positive & $1(10.0)$ & $1(0.8)$ & - \\
\hline Negative & $9(90.0)$ & $126(99.2)$ & - \\
\hline Satellitosis - n (\%) & & & 0.505 \\
\hline Positive & $1(10.0)$ & $8(6.3)$ & - \\
\hline Negative & $9(90.0)$ & 119 (93.7) & - \\
\hline Mitoses - n (\%) & & & 0.686 \\
\hline Positive & $9(90.0)$ & 101 (79.5) & - \\
\hline Negative & $1(10.0)$ & $26(20.5)$ & - \\
\hline
\end{tabular}

*Statistical tests used: Student, Mann-Whitney, Fisher's exact, Pearson's chi-square 
TABLE 2: Multivariate analysis* to evaluate independent factors associated to sentinel lymph node involvement in thin primary cutaneous melanomas (2003-2015, Laboratory of Pathology, Santa Casa de Porto Alegre, Brazil); $=137$

\begin{tabular}{lc} 
Variables & Odds Ratio (95\% CI) \\
\hline Sex & $3.10(0.75-12.9)$ \\
Male & 1.0 \\
Female & \\
Clark & 1.0 \\
I/II & $4.43(0.40-49.7)$ \\
III & $4.11(0.28-60.4)$ \\
IV/V & 1.0 \\
Intensity of TIL & $0.20(0.05-0.72)$ \\
Negative/Few & \\
Moderate/Marked & $0.63(0.17-2.39)$ \\
Regression & 1.0 \\
Positive & \\
Negative & $12.8(2.77-59.4)$ \\
Ulceration & 1.00 \\
Positive & \\
Negative &
\end{tabular}

*Poisson regression

However, the use of this information in the early management of TPCM is limited. In the studies by Burton et al. ${ }^{23}$ and Duprat et al. ${ }^{24}$, the active presence of TIL demonstrated sentinel lymph node protection in melanomas thicker than $1 \mathrm{~mm}$. In the studies by Fortes et al. ${ }^{19}$, Mandala et al..$^{25}$ and Taylor et al. ${ }^{26}$, TPCM were included with

\section{REFERENCES}

1. Sloot S, Speijers MJ, Bastiaannet E, Hoekstra HJ. Is there a relation between type of primary melanoma treatment and the development of intralymphatic metastasis? A review of the literature. Cancer Treat Rev. 2016;45:120-8.

2. Koshenkov VP, Broucek J, Kaufman HL. Surgical Management of Melanoma Cancer Treat Res. 2016;167:149-79.

3. Hieken TJ, Grotz TE, Comfere NI, Inselman JW, Habermann EB. The effect of the AJCC 7th edition change in T1 melanoma substaging on national utilization and outcomes of sentinel lymph node biopsy for thin melanoma. Melanoma Res. 2015;25:157-63.

4. Gimotty PA, Botbyl J, Soong SJ, Guerry D. A population-based validation of the American Joint Committee on Cancer melanoma staging system. J Clin Oncol. 2005;23:8065-75.

5. Han D, Yu D, Zhao X, Marzban SS, Messina JL, Gonzalez RJ, et al. Sentinel node biopsy is indicated for thin melanomas $\geq 0.76 \mathrm{~mm}$. Ann Surg Oncol. 2012;19:3335-42.

6. Han D, Zager JS, Shyr Y, Chen H, Berry LD, lyengar S, et al. Clinicopathologic predictors of sentinel lymph node metastasis in thin melanoma. J Clin Oncol. 2013:31:4387-93.

7. Vermeeren L, Van der Ent F, Sastrowijoto P, Hulsewé K.. Sentinel lymph node biopsy in patients with thin melanoma: occurrence of nodal metastases and its prognostic value. Eur J Dermatol. 2010;20:30-4.

8. Jacobs IA, Chang CK, DasGupta TK, Salti GI. Role of sentinel lymph node biopsy in patients with thin (<1 mm) primary melanoma. Ann Surg Oncol. 2003;10:558-61. the thicker melanomas and the group demonstrated a higher risk for SLNB positivity when TIL was absent or few/inactive. Azimi presented similar results to those authors but the analysis was of all primary cutaneous melanoma and the thin group was limited to thickness between 0.75 to $1.0 \mathrm{~mm} .^{18}$

The presence of mitoses did not constitute risk for sentinel lymph node positivity $(\mathrm{p}=0.686)$, contrary to what was observed by Kesmodel et al. $^{27}$

It is extremely important to consider that local control of the disease in patients with lymph node involvement can improve disease- and recurrence-free survival when done early (SNLB followed by lymphadenectomy), with better local control of the disease (avoiding lymph node tumor masses, many times associated to ulceration, infection and bleeding, situations of difficult clinical management and great suffering for the patient), despite not improving overall..$^{28-35}$

As limitation of the study, the coherence with studies by Azimi et al. ${ }^{18}$ and Fortes $e t$ al. ${ }^{19}$ in the characterization of ulceration as a risk factor for sentinel lymph node should be evaluated carefully, because even by demonstrating a significantly high risk (12.8-fold), the number of cases of ulcerated melanomas was small in both groups.

In the present study with 137 TPCM cases, we observed that the risk for SLNB positivity is not negligible (7.3\%) and regardless of other risk factors, absent or few TIL presents as a risk factor for sentinel lymph node positivity on TPCM. Thus, it is important to take TIL into consideration in the group of information that will define which TPCM can benefit from SLNB.

\section{CONCLUSION}

The evaluation of the presence and intensity of TIL in invasive TPCM patients can help in the decision-making to perform SLNB. $\square$
9. Wong SL, Brady MS, Busam KJ, Coit DG. Results of sentinel lymph node biopsy in patients with thin melanoma. Ann Surg Oncol. 2006;13:302-9.

10. Doepker MP, Zager JS. Sentinel lymph node mapping in melanoma in the twentyfirst century. Surg Oncol Clin N Am. 2015;24:249-60.

11. Fearfield LA, Rowe A, Francis N, Fisher C, Gore ME, Bunker CB. Clinicopathological features of relapsing very thin melanoma. Clin Exp Dermatol. 2001;26:686-95.

12. Andtbacka RH, Gershenwald JE. Role of sentinel lymph node biopsy in patients with thin melanoma. J Natl Compr Canc Netw. 2009;7:308-17.

13. Hu-Lieskovan S, Robert L, Homet Moreno B, Ribas A. Combining Targeted Therapy With Immunotherapy in BRAF-Mutant Melanoma: Promise and Challenges. J Clin Oncol. 2014;32:2248-54.

14. Shah DJ, Dronca RS. Latest advances in chemotherapeutic, targeted, and immune approaches in the treatment of metastatic melanoma. Mayo Clin Proc. 2014;89:504-19.

15. Redman JM, Gibney GT, Atkins MB. Atkins. Advances in immunotherapy for melanoma. BMC Med. 2016;14:20.

16. Mihm MC Jr, Mulé JJ. Reflections on the Histopathology of Tumor-infiltrating Lymphocytes in Melanoma and the Host Immune Response. Cancer Immunol Res. 2015:3:827-35.

17. Elder DE, Guerry D 4th, VanHorn M, Hurwitz S, Zehngebot L, Goldman L, et al. The role of lymph node dissection for clinical stage I malignant melanoma of intermediate thickness (1.51-3.99 mm). Cancer. 1985;56:413-8. 
18. Azimi F, Scolyer RA, Rumcheva P, Moncrieff M, Murali R, McCarthy SW, et al Tumor-infiltrating lymphocyte grade is an independent predictor of sentinel lymph node status and survival in patients with cutaneous melanoma. J Clin Oncol. 2012;30:2678-83.

19. Fortes C, Mastroeni S, Mannooranparampil TJ, Passarelli F, Zappalà A, Anness $\mathrm{G}$, et al.Tumor-infiltrating lymphocytes predict cutaneous melanoma survival. Melanoma Res. 2015;25:306-11.

20. Clemente CG, Mihm MC Jr, Bufalino R, Zurrida S, Collini P, Cascinelli N. Prognostic value of tumor infiltrating lymphocytes in the vertical growth phase of primary cutaneous melanoma. Cancer. 1996;77:1303-10.

21. Tuthill RJ, Unger JM, Liu PY, Flaherty LE, Sondak VK; Southwest Oncology Group. Risk assessment in localized primary cutaneous melanoma: a Southwest Oncology Group study evaluating nine factors and a test of the Clark logistic regression prediction model. Am J Clin Pathol. 2002;118:504-11.

22. Thomas NE, Busam KJ, From L, Kricker A, Armstrong BK, Anton-Culver H, et al. Tumor-infiltrating lymphocyte grade in primary melanomas is independently associated with melanoma-specific survival in the population-based genes, environment and melanoma study. J Clin Oncol. 2013;31:4252-9.

23. Burton AL, Roach BA, Mays MP, Chen AF, Ginter BA, Vierling AM, et al. Prognostic significance of tumor infiltrating lymphocytes in melanoma. Am Surg. 2011;77:188-92

24. Duprat JP, Brechtbülh ER, Costa de Sá B, Enokihara M, Fregnani JH, Landman $G$, et al. Absence of Tumor-Infiltrating Lymphocyte Is a Reproducible Predictive Factor for Sentinel Lymph Node Metastasis: A Multicenter Database Study by the Brazilian Melanoma Group. PLoS One. 2016;11:e0148160.

25. Mandalà M, Imberti GL, Piazzalunga D, Belfiglio M, Labianca R, Barberis M, et al.Clinical and histopathological risk factors to predict sentinel lymph node positivity, disease-free and overall survival in clinical stages I-II AJCC skin melanoma: outcome analysis from a single-institution prospectively collected database. Eur J Cancer. 2009;45:2537-45.
26. Taylor RC, Patel A, Panageas KS, Busam KJ, Brady MS. Tumor-infiltrating lymphocytes predict sentinel lymph node positivity in patients with cutaneous melanoma. J Clin Oncol. 2007;25:869-75

27. Kesmodel SB, Karakousis GC, Botbyl JD, Canter RJ, Lewis RT, Wahl PM. Mitotic rate as a predictor of sentinel lymph node positivity in patients with thin melanomas. Ann Surg Oncol. 2005;12:449-58.

28. Nagaraja V, Eslick GD. Is complete lymph node dissection after a positive sentinel Lymph node biopsy for cutaneous melanoma always necessary? A metaanalasys. Eur J Surg Oncol. 2013;39:669-80.

29. Sondak VK, Wong SL, Gershenwald JE, Thompson JF. Evidence-based clinical practice guidelines on the use of sentinel lymph node biopsy in melanoma. Am Soc Clin Oncol Educ Book. 2013.33.e320.

30. Morton DL, Thompson JF, Cochran AJ, Mozzillo N, Nieweg OE, Roses DF, et al. Final trial report of sentinel-node biopsy versus nodal observation in melanoma. $\mathrm{N}$ Engl J Med. 2014;370:599-609.

31. Kyrgidis A, Tzellos T, Mocellin S, Apalla Z, Lallas A, Pilati P, et al. Sentinel lymph node biopsy followed by lymph node dissection for localised primary cutaneous melanoma. Cochrane Database Syst Rev. 2015;CD010307.

32. Costa Svedman F, Spanopoulos D, Taylor A, Amelio J, Hansson J. Surgical outcomes in patients with cutaneous malignant melanoma in Europe - a systematic literature review. J Eur Acad Dermatol Venereol. 2017;31:603-15.

33. Bleicher RJ, Essner R, Foshag LJ, Wanek LA, Morton DL. Role of sentinel lymphadenectomy in thin invasive cutaneous melanomas. J Clin Oncol. 2003;21:1326-31.

34. Wong SL, Balch CM, Hurley P, Agarwala SS, Akhurst TJ, Cochran A, et al. Sentinel lymph node biopsy for melanoma: American Society of Clinical Oncology and Society of Surgical Oncology joint clinical practice guideline. Ann Surg Oncol. 2012;19:3313-24

35. Leilabadi SN, Chen A, Tsai S, Soundararajan V, Silberman H, Wong AK. Update and Review on the Surgical Management of Primary Cutaneous Melanoma. Healthcare (Basel). 2014;2:234-49.

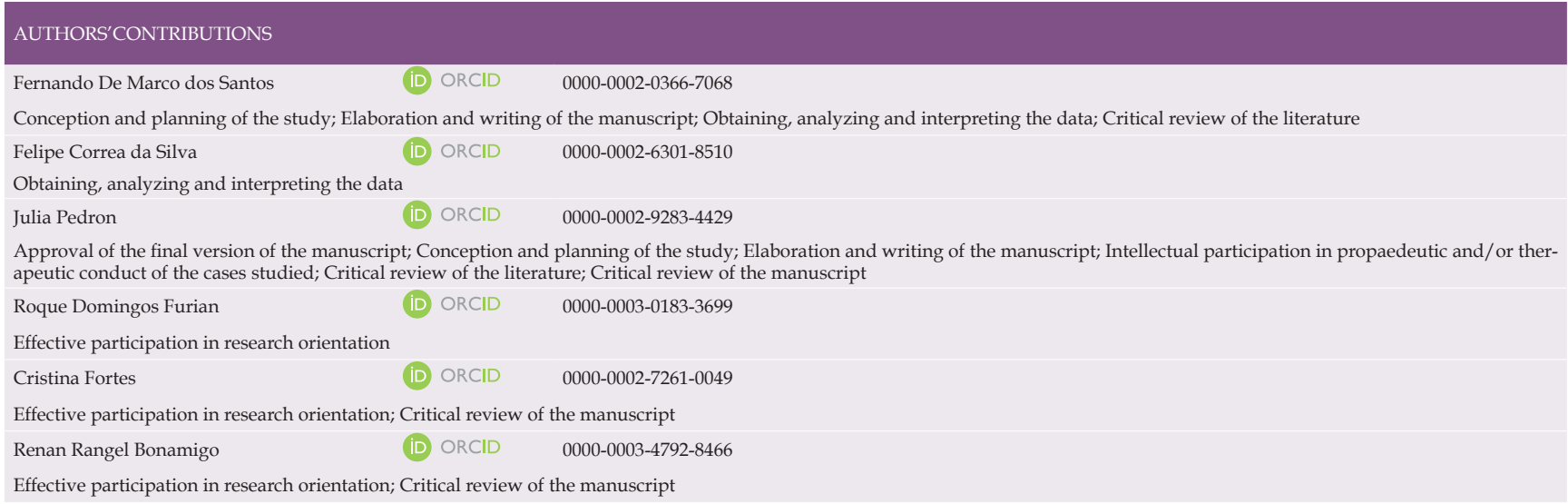

How to cite this article: Santos FM, Silva FC, Pedron J, Furian RD, Fortes C, Bonamigo RR. Association between tumor-infiltrating lymphocytes and sentinel lymph node positivity in thin melanoma. An Bras Dermatol. 2019;94(1):47-51. 